\title{
Políticas públicas para as Altas Habilidades/ Superdotação: incluir ainda é preciso
}

\author{
Susana Graciela Pérez Barrera Pérez* \\ Soraia Napoleão Freitas**
}

\section{Resumo}

O presente artigo analisa as políticas públicas brasileiras para alunos com Altas Habilidades/Superdotação (AH/SD), considerando a legislação vigente, verificando como causas da carência e precariedade dessas políticas o atrelamento da oferta do atendimento educacional especializado a uma demanda que ainda não é aferida; a deficiente compreensão das realidades educacionais regionais; a circunscrição dos dispositivos exclusivamente ao âmbito educacional; o pouco conhecimento (ou mesmo desconhecimento) das leis, normas e documentos norteadores e das reais dificuldades e necessidades destes estudantes e o preconceito ideológico. Conclui que a real inclusão dos alunos com AH/SD requer a correta identificação e registro desses estudantes nos censos escolares; a promoção de um conhecimento mais aprofundado da legislação, normas e documentos norteadores e de sua fiscalização pelos poderes públicos; a necessária formação inicial e continuada de professores, profissionais e gestores sobre as AH/SD e suas necessidades; o apoio técnico e financeiro e a fiscalização do trabalho desenvolvido pelos Núcleos de Atividades de Altas Habilidades/Superdotaçáo. Requer, também, mecanismos legais que garantam o acesso ao atendimento educacional especializado da grande maioria de estudantes com AH/SD brasileiros, filhos de famílias de classes desfavorecidas, que não possuem recursos financeiros e/ou culturais para garantir esse direito, assim como a eliminação das barreiras econômicas, culturais e atitudinais como objetivo dos dispositivos que garantem a acessibilidade das pessoas com necessidades educacionais especiais; a indispensável inclusão de módulos de formação específica para o atendimento educacional especializado nos cursos de capacitação e especialização oferecidos pelos órgãos públicos e, finalmente, a eliminação do infundamentado preconceito ideológico.

Palavras-chave: Altas Habilidades/Superdotação; Políticas públicas; Inclusão.

\footnotetext{
* Doutora em Educação pela PUC/RS, Presidente e sócia fundadora do ConBraSD, membro do Conselho técnico da Associação Gaúcha de Apoio às Altas Habilidades/Superdotação. Porto Alegre, Rio Grande do Sul, Brasil.

** Professora Doutora da Universidade Federal de Santa Maria (UFSM). Santa Maria, Rio Grande do Sul, Brasil.
} 


\section{Public Policies for High Ability/Giftedness: Including is Still Necessary}

\section{Abstract}

This paper examines the Brazilian public policies for students with High Abilities/ Giftedness (HA/GT), considering the currently ruling laws, verifying as causes of lack and precariousness of such policies, the dependence of specialized educational service offer to a demand still not assessed; the deficient understanding of regional educational realities, the circumscription of legal documents exclusively to the educational context; the poor knowledge (or even lack of knowledge) of laws, rules and guidelines and of real difficulties and needs of such students and the ideological prejudice. It concludes that the real inclusion of students with HA/GT requires the correct identification and record of such students in the school census; the promotion of a deeper knowledge on laws, rules and guidelines and its inspection by public agencies; the necessary initial and continued education of teachers, professionals and school managers on HA/GT and their needs; the technical and financial support and control of the work developed by the Centers of Activities on HA/GT. It also requires legal mechanisms assuring the access to the specialized educational services to most Brazilian students with HA/GT, children of low income families who have no financial and/or cultural resources to assure such right, as well as the elimination of economic, cultural and attitudinal barriers as object of the legal devices granting accessibility to people with special educational needs; the indispensable inclusion of specific educational modules on special educational services in training and specialization courses offered by public agencies and, finally, the elimination of the unfounded ideological prejudice.

Keywords: High Abilities/Giftedness; Public policies; Inclusion.

\section{A história recente da legalidade de um ser humano ainda excluído}

Embora as Altas Habilidades/Superdotação existam desde que o homem é homem e este não seja, ao contrário do que se costuma dizer, "um tema novo", a preocupação das políticas públicas com essa enorme parcela da população que apresenta esse comportamento somente começa a manifestar-se, no Brasil, no início da década de 70 do século passado.

A Lei de Diretrizes e Bases da Educação Nacional de 1971 (Lei 5692/71) é a primeira a distinguir os alunos superdotados do genérico termo "excepcionais", utilizado na LDBEN, de 1961, para caracterizar os alunos com necessidades educacionais especiais, e a determinar que eles (assim como os que apresentassem deficiências físicas ou mentais) deveriam ser alvo de "tratamento especial, de acordo com as normas fixadas pelos competentes Conselhos de Educação" (BRASIL, 1971). Talvez essa diferenciação fosse responsável por chamar a atenção para a existência desses alunos. 
Nesse momento, também ocorriam discussóes mais, intensas nos Estados Unidos e, em 1972, o Relatório Marland (MARLAND, 1972), encomendado pelo Congresso daquele país, além de estabelecer a primeira definição nacional de superdotação, relata uma situação em relação às Altas Habilidades/Superdotação que não é muito diferente das condiçôes atuais no nosso País. Dentre elas, o Relatório destacava o enorme número de alunos superdotados existente no país e a pequena fração deles efetivamente atendida na Educação; a reduzida prioridade outorgada ao atendimento especializado por parte das autoridades federais, estaduais e municipais; a ineficácia das legislaçóes existentes; a falta de recursos destinados à educação de alunos com AH/SD; a dificuldade de identificação, ainda mais prejudicada pela apatia e hostilidade de professores, gestores, orientadores e psicólogos; a inexistência de serviços de atendimento efetivos; a dependência das secretarias estaduais e municipais da liderança do governo federal e a ineficácia do órgão federal em ofertar atendimento para os alunos com AH/SD.

Outro grande balizador do caminho que levou à implementação de uma política pública educacional para as AH/SD foi a Lei de Diretrizes e Bases da Educação Nacional (Lei 9394/96) que revogou a sua congênere de 1971, avançando um pouco mais ao definir os superdotados como alunos com necessidades educacionais especiais (BRASIL, 1996), por força da definição desta população na Política Nacional de Educação Especial, formulada em 1994.

No novo milênio, encontramos documentos mais claros ainda, tais como o Plano Nacional de Educação (Lei 10.172/01) que, além de reconhecer a precariedade das estatísticas oficiais quanto aos alunos com AH/SD, define como uma de suas metas e objetivos: "implantar gradativamente, a partir do primeiro ano deste plano, programas de atendimento aos alunos com altas habilidades nas áreas artística, intelectual ou psicomotora" (BRASIL, 2001), e as Diretrizes Nacionais de Educação Especial na Educação Básica (Parecer No 17 e Resolução No 2) (BRASIL, 2002), que especificam o tipo de atendimento que os alunos com AH/SD devem receber.

Em 2008, a Política Nacional de Educaçâo Especial na Perspectiva da Educação Inclusiva incorpora importantes mudanças, especialmente no que se refere à troca paradigmática da integração para a inclusão; ao público-alvo; agora composto por alunos com deficiência, Transtornos Globais do Desenvolvimento e Altas Habilidades/Superdotação; à ampliaçáo do espectro de atuação da Educação Especial da Educação Infantil até o Ensino Superior, antes limitado ao ensino básico e à oferta de atendimento educacional especializado (AEE) em todos os níveis e modalidades de ensino. O Decreto No 6571/08, promulgado no mesmo ano, vem reforçar a Política, destinando aos alunos com necessidades educacionais especiais o dobro dos recursos do FUNDEB repassados às escolas que ofereçam AEE, e o Parecer No 13 e a Resoluçáo No 4 do Conselho Nacional de Educação/Câmara de Educaçáo Básica instituem as Diretrizes Operacionais para o Atendimento Educacional Especializado, especificando como, quando, onde e quem o oferecerá. O Decreto foi substituído pelo de No 7611/11, de 17 de novembro de 2011, que "dispóe sobre a Educação Especial, o atendimento educacional especializado e dá outras providências" (BRASIL, 2011), mantendo basicamente as mesmas disposiçóes que o Decreto 6571/08, no que se refere às $\mathrm{AH} / \mathrm{SD}$. 
Esses documentos inscrevem os direitos da comunidade escolar nas leis e normas educacionais e poderiam garantir a sua permanência após as mudanças de governo, como afirma Prieto (2002); porém, não constituem garantia da implantação de políticas públicas eficientes.

Embora as leis educacionais brasileiras sejam muito avançadas no contexto internacional, é necessário revisar (e refletir sobre) que pressupostos teóricos e que princípios determinam as açôes e programas que concretizam, na prática, as políticas públicas brasileiras.

As leis, normas e documentos norteadores educacionais, então, determinam e asseguram o direito ao AEE dos estudantes com AH/SD, mas a sua execução e a sua aplicabilidade ficam comprometidas por diversos fatores: o atrelamento da oferta a uma demanda não aferida; a deficiente compreensão das realidades educacionais regionais; a circunscrição dos dispositivos exclusivamente ao âmbito educacional; o pouco conhecimento (ou mesmo desconhecimento) dessas leis, normas e documentos norteadores e das reais dificuldades e necessidades destes estudantes e o preconceito ideológico.

\section{atrelamento da oferta a uma demanda não aferida}

$\mathrm{Na}$ área da Educação, segundo refere o Instituto Nacional de Pesquisas e Estudos Educacionais Anísio Teixeira (INEP), órgão responsável pelas estatísticas educacionais, os dados do Censo Escolar "constituem a mais completa fonte de informaçóes utilizada pelo Ministério da Educação para a formulação de políticas e para o desenho de programas" (2009). Para ajustar a oferta de açóes e programas à demanda existente, é necessário que essa demanda seja corretamente aferida, o que não ocorre no Brasil, pelo menos quando se consideram os dados do Censo Escolar.

No Censo da Educação Básica de 2012, somente 11.025 dos mais de 2,5 milhóes de alunos com AH/SD, conforme as estimativas, de acordo com as leis da probabilística, foram registrados como tais, sendo $10.902 \mathrm{em}$ classes comuns e os restantes 123 em classes especiais. Isso explicaria a escassez de serviços públicos de atendimento educacional para os estudantes com $\mathrm{AH} / \mathrm{SD}$, que contam apenas com os 27 Núcleos de Atividades de Altas Habilidades/Superdotação (NAAH/S) implantados em 2005, em todas as capitais brasileiras. Se o número real de alunos fosse o registrado no censo, talvez a distribuição de estudantes por NAAH/S permitisse atendê-los de uma forma relativamente adequada, pelo menos no âmbito educacional; porém, esse número não representa sequer $0,004 \%$ das estimativas da Educação Básica e apenas 0,02\% das matrículas de 2013 . O próprio resumo técnico do Censo Escolar de 2013, deixa clara a visáo que o INEP tem das AH/SD como público alvo da Educação Especial, quando omite a área ao referir:

Em 2012, esses números alcançaram 78,2\% nas públicas e 21,8\% nas escolas privadas, mostrando a efetivação da educação inclusiva e o empenho das redes de ensino em envidar esforços para organizar uma política pública universal e acessível às pessoas com deficiência. (BRASIL, 2013, p. 28) 
No ensino superior, no qual, pelas mesmas estimativas, existiam, em 2011, mais de 338.000 estudantes com AH/SD, havia apenas 953 alunos com AH/SD declarados. Consequentemente, ainda não há normativa legal mais concreta que operacionalize o AEE para esses alunos, apesar da tímida disposição da LDBEN de 1996, que aventa a possibilidade de aceleração ou avanço no seu Artigo 47, quando determina, no $\$ 2$, que:

Os alunos que tenham extraordinário aproveitamento nos estudos, demonstrado por meio de provas e outros instrumentos de avaliação específicos, aplicados por banca examinadora especial, poderão ter abreviada a duração dos seus cursos, de acordo com as normas dos sistemas de ensino. (BRASIL 1996, p. 12)

Talvez a promulgação da nova Política de Educação Especial na Perspectiva da Educação Inclusiva, que determina que seu âmbito de aplicação, agora, deve estender-se à Educaçáo Superior, provoque a formulação de alguma norma mais concreta nesse sentido, visto que a aceleração é apenas uma medida administrativa, mas não uma estratégia pedagógica. Entretanto, se a oferta de AEE ficar atrelada aos dados dos censos de Educação Superior, como ocorre na Educação Básica, provavelmente nada mudará, simplesmente porque após ter ficado de fora do formulário do Censo de 2009, a categoria Altas Habilidades/Superdotação reaparece em 2011, com um número minúsculo de alunos registrados (INEP, 2011).

\section{A deficiente compreensão das realidades educacionais regionais}

As enormes diferenças regionais (sociais, culturais e econômicas), existentes num País como o nosso, são um fator que também dificulta o AEE para os alunos com AH/SD.

Enquanto alguns estados e municípios já estão implantando o AEE apenas para os alunos com deficiência, o que já representa um grande avanço, outros ainda tentam entender a importância de aceitar, respeitar, reconhecer (e atender) a diversidade. Isso tem reflexo direto nas escolas, reprodutoras e mantenedoras dos valores sociais de cada comunidade, e, logicamente, na priorização de suas práticas pedagógicas.

Em outros, os escassos investimentos na Educação e, particularmente, na Educação Especial, são ainda agravados pela precária formação dos seus gestores e professores, pela insuficiente remuneração dos seus professores e pela defasagem no acesso a informaçôes mais atualizadas.

Por se tratar de um tema ainda não aprofundado na Educação Especial, geralmente não associado a ela, e povoado de mitos e crenças populares, as AH/SD não são incluídas nos cursos de formação inicial nem continuada; não se considera a possibilidade de atendimento nas Salas de Recursos Multifuncionais (às quais são encaminhados apenas os alunos com deficiência) e os estudantes que apresentam esse comportamento não são identificados, acreditando-se que eles não existem. 
O apoio e manutenção dos NAAH/S pelas Secretarias Estaduais de Educação, que tiveram essa responsabilidade acordada quando do estabelecimento da parceria com o MEC, na sua implantaçáo, também são muito díspares no País. Enquanto alguns desenvolvem um excelente trabalho, qualificando, identificando e inclusive atendendo a população de estudantes com AH/SD, mesmo em estados sem trajetória de pesquisa e de atendimento na área, outros estáo simplesmente desativados ou ameaçados de extinçâo, inclusive em estados que têm significativa representatividade na área, no que se refere à produçáo científica ou pionerismo no atendimento educacional.

O programa Educação Inclusiva: Direito à Diversidade, da Secretaria de Alfabetização, Diversidade e Inclusão do MEC, que é oferecido aos municípios brasileiros, é uma instância de formação que permite abordar o tema das AH/SD. Entretanto, por totalizar 40 horas de formação por ano, apenas, geralmente, restringe o contato dos professores com o tema a uma sensibilização muito superficial (4 ou 8 horas, como máximo), quando há, que não é suficiente para trabalhar aspectos que são fundamentais para o desenvolvimento do atendimento.

A Lei de Diretrizes e Bases da Educação Nacional de 1996 definia, no item III do seu artigo No 59, que os sistemas de ensino assegurarão "III - professores com especialização adequada em nível médio ou superior, para atendimento especializado" (BRASIL 1996, s. p.), exigência referendada no Artigo 18 da Resoluçáo No 2 (BRASIL 2002), e o Artigo 12 da Resolução No 4 do Conselho Nacional de Educação/ Câmara de Educação Básica determina que "para atuação no AEE, o professor deve ter formação inicial que o habilite para o exercício da docência e formação específica para a Educação Especial' (BRASIL, 2009, p. 3, grifos meus). A interpretação dessas disposiçóes tem causado bastante dúvida entre os gestores e professores, que alegam não atender aos alunos com $\mathrm{AH} / \mathrm{SD}$ porque não possuem formação específica na área que lhes permita cumprir com o inciso I do Artigo 13 da mesma resolução, "identificar, elaborar, produzir e organizar serviços, recursos pedagógicos, de acessibilidade e estratégias considerando as necessidades específicas dos alunos público-alvo da Educação Especial" (BRASIL. 2009, p. 3).

Algumas Secretarias Estaduais exigem que o professor que atende a Sala de Recursos Multifuncionais tenha formação em nível de especialização, o que cria outro impasse quanto ao $\mathrm{AEE}$ para estudantes com $\mathrm{AH} / \mathrm{SD}$, visto que é inexistente a oferta de Cursos de Especialização em Altas Habilidades/Superdotação nas universidades brasileiras, reforçando e "justificando" a ausência de serviços de atendimento educacional em nível estadual. Por outro lado, alguns estados que possuíam salas de recursos específicas para alunos com $\mathrm{AH} / \mathrm{SD}$, com profissionais especializados na área, estão transformando essas salas em Salas de Recursos Multifuncionais, que deverão atender a todos os alunos (entenda-se, aqui, alunos com deficiência, TGD e AH/ $\mathrm{SD})$, reduzindo ainda mais a oferta de $\mathrm{AEE}$ para os estudantes com $\mathrm{AH} / \mathrm{SD}$, visto que o contrário não ocorre. Enquanto existem milhares de professores especialistas em Educação Especial com habilitação nas diferentes áreas de deficiência, o número de profissionais com o mesmo nível de formação na área de AH/SD é extremamente 
pequeno e, no momento que nas salas de recursos específicas para AH/SD também passem a ser atendidos os estudantes com deficiência e TGD, o número de alunos com $\mathrm{AH} / \mathrm{SD}$ atendidos ou que poderiam vir a ser atendidos também será reduzido para dar lugar aos demais alunos com necessidades educacionais especiais que têm espaço garantido em todas as Salas de Recursos Multifuncionais do País.

\section{A circunscrição dos dispositivos exclusivamente ao âmbito educacional}

A falta de interface com as políticas públicas nos demais âmbitos sociais também prejudica o atendimento educacional especializado aos alunos com AH/SD. A escassez de salas ou centros especializados para o AEE de estudantes com AH/SD faz com que a localização geográfica seja centralizada geralmente nas capitais.

Segundo a Pesquisa Nacional por Amostra de Domicílios de 2008 (PNAD) do IBGE, 71,7\% do povo brasileiro ganha até 3 salários mínimos (IBGE, 2008) e esses dados não são diferentes para as famílias das Pessoas com AH/SD; dessa forma, as barreiras econômicas comprometem profundamente o acesso à Educação desses alunos, visto que, a diferença dos estudantes com deficiência, que têm garantido o passe livre no transporte urbano, interurbano e interestadual, não existe qualquer tipo de dispositivo que lhes permita freqüentar o AEE sem comprometer o orçamento familiar. Qualquer transporte até as capitais dos estados brasileiros e mesmo dentro do âmbito das capitais (onde estáo localizados os NAAH/S), envolve uma desestruturação do orçamento familiar que a maioria dessas famílias não consegue suportar. Como resultado, há uma grande desistência dos pouquíssimos estudantes identificados e candidatos ao AEE, mesmo quando se trata de alunos residentes nas capitais que poderiam ser atendidos nas salas de recursos sediadas nesses centros.

A acessibilidade, então, geralmente compreendida como a eliminação de barreiras arquitetônicas e de comunicação para os estudantes com deficiência, agrega a necessidade de eliminar também as barreiras econômicas, além das tradicionais barreiras culturais, atitudinais e pedagógicas que devem ser combatidas para promover a inclusão dos alunos com AH/SD.

No AEE para alunos com deficiência, é muito comum estabelecer parcerias com as Secretarias de Trabalho e/ou serviços não-governamentais para a promoção de oportunidades de trabalho diferenciadas. Embora a LDB (Art. 59, IV) determinasse que os alunos com necessidades educacionais especiais devessem receber educação especial para o trabalho para facilitar a inserção na vida em sociedade e condiçóes adequadas, por meio da articulação com órgãos oficiais afins, "bem como para aqueles que apresentam uma habilidade superior nas áreas artística, intelectual ou psicomotora” (BRASIL 1996, s.p.), essa disposição não é cumprida para os últimos.

Outras políticas públicas também poderiam contemplar os estudantes com AH/SD, no âmbito da assistência social, do trabalho e da cultura, como o fazem com os demais alunos com necessidades educacionais especiais, mas, por ora, ainda estấo muito distantes de serem consideradas, pelo menos até que a Pessoa com AH/SD não tenha seu direito à identidade reconhecido, na sociedade. De fato, a LDBEN defi- 
nia, no art. 59, V, que os sistemas de ensino deveriam assegurar aos educandos com necessidades educacionais especiais "acesso igualitário aos benefícios dos programas sociais suplementares disponíveis para o respectivo nível do ensino regular" (BRASIL 1996 , s.p.).

\section{O pouco conhecimento (ou mesmo desconhecimento) das leis, normas e documentos norteadores e das reais dificuldades e necessidades destes estudantes}

O pouco conhecimento e mesmo o desconhecimento da legislação educacional pelos professores, gestores e pelas próprias famílias dos estudantes com AH/SD é uma constatação muito freqüente, especialmente dos dispositivos que determinam os seus direitos.

A obrigatoriedade do AEE para estes estudantes não raramente é uma surpresa para as administraçóes escolares públicas e mais ainda, para as das escolas privadas que desconhecem que a legislação educacional estende suas normas também a elas.

$\mathrm{O}$ mesmo ocorre com as reais dificuldades e necessidades dos estudantes com AH/SD; esse é um fato constante entre os professores, gestores e legisladores, que está intrínseco em grande parte dos fatores anteriormente citados, afetando diretamente a identificação e o registro nos censos escolares, o atendimento educacional e a formulação de políticas públicas eficientes e eficazes.

Uma grande parte dos cursos de graduação, especialmente os de Pedagogia e Educação para cumprir com a recomendação da Portaria 1793/94 de incluir a disciplina Aspectos ético-político-educacionais da normalização e integração da pessoa portadora de Necessidades especiais nos cursos de Pedagogia, Psicologia e em todas as licenciaturas e nos cursos de graduação das demais áreas, destinam uma pequena carga horária para discutir, de forma muito generalizada, a Educação Especial.

Entretanto, como afirma Moreira (2009, p. 268), "as universidades ainda carecem de uma formação que viva a inclusão e ultrapasse a linearidade e a simplificação curricular de que basta uma disciplina sobre a área da NEE para formar professores capacitados a atuarem com o alunado que apresenta necessidades mais específicas".

Os professores graduados em cursos universitários de qualquer área raramente tiveram conteúdos relacionados às $\mathrm{AH} / \mathrm{SD}$ na sua formação inicial, e essa também é uma afirmação praticamente unânime dos pedagogos, psicólogos e educadores de todos os cantos do País. Nos cursos "do grupo de Ciência da Saúde (Educação Física, Enfermagem, Farmácia, Fisioterapia, Fonoaudiologia, Medicina, Nutrição, Odontologia, Terapia Ocupacional), no Curso de Serviço Social e nos demais cursos superiores, de acordo com as suas especificidades", aos quais também se aplica a recomendação da Portaria 1793/94, e, especialmente nos cursos de Psiquiatria e Neurologia, a realidade não é diferente e o resultado dessa carência é ainda mais preocupante, devido à confusão constante entre os sintomas de patologias e os indicadores de $\mathrm{AH} / \mathrm{SD}$. O crescente e alarmante número de estudantes com AH/SD diagnosticados 
equivocadamente como sendo acometidos de Transtorno de Déficit de Atenção com ou sem hiperatividade, transtorno bipolar, depressão ou Síndrome de Asperger e até autismo e medicados para tratar esses quadros, expóe uma situação extremamente preocupante que somente poderá ser sanada quando esses profissionais da saúde tiverem em seus currículos de formação superior os conteúdos programáticos necessários para desfazer esse erro.

$\mathrm{Na}$ área da formação específica para o AEE, constata-se que um dos recursos recentes para sanar as carências de formação, os cursos de especialização e de capacitação em AEE oferecidos pela SEESP/MEC (BRASIL, 2010) na modalidade a distância, em parceria com universidades brasileiras e os materiais disponibilizados no site sobre o tema incluem os módulos de "AEE - Pessoa com Surdez; AEE - Deficiência Física; AEE - Deficiência Mental e AEE - Deficiência Visual”, além de um módulo de "Orientaçôes Gerais e Educação a distância", não apresentando cursos nem materiais sobre o AEE para pessoas com AH/SD. Os professores que estão atualmente participando dos cursos de formação para o $\mathrm{AEE}$ não conseguem compreender como os estudantes com AH/SD podem ser alunos com necessidades educacionais especiais e nem por que devem ser atendidos nas salas de recursos multifuncionais se, nas formaçôes específicas, não se fala sobre eles.

A freqüente associação equivocada das $\mathrm{AH} / \mathrm{SD}$ ao desempenho escolar extraordinário, à criatividade, à precocidade, ou à genialidade, de forma isolada, provoca muita confusão na identificação e banaliza o conceito teórico que deve ser definido, esclarecido e explicitado nos documentos educacionais. A falta de um conhecimento aprofundado sobre o tema conduz a recomendaçóes levianas, como as verificadas nos Parâmetros Curriculares Nacionais - Adaptaçóes curriculares, Estratégias para a educação de alunos com necessidades educacionais especiais (BRASIL, 1998) que, para os alunos com AH/SD, aconselham, como alteração da seleção e adaptação de materiais, o "uso de calculadora científica", e como recursos de acesso ao currículo, sugerem:

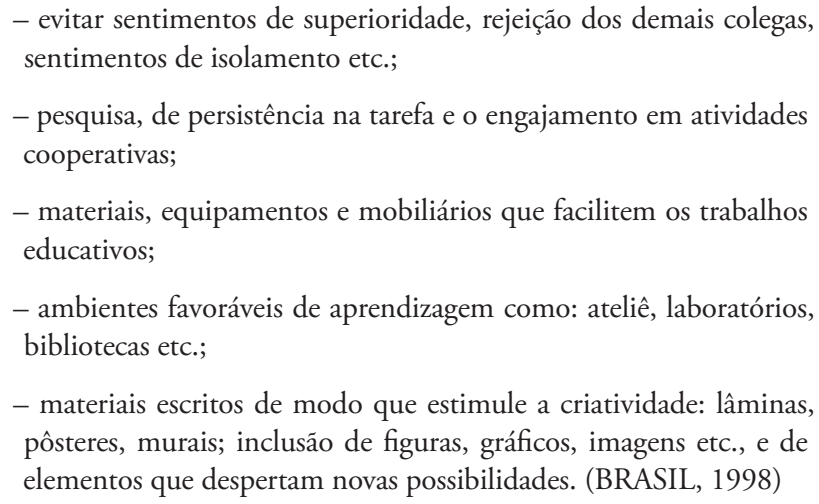

- materiais escritos de modo que estimule a criatividade: lâminas, pôsteres, murais; inclusão de figuras, gráficos, imagens etc., e de elementos que despertam novas possibilidades. (BRASIL, 1998)

Essas sugestôes revelam algumas idéias erroneamente preconcebidas sobre as Altas Habilidades/Superdotação que estão embutidas nos Parâmetros Curriculares Nacionais - Adaptaçôes curriculares Estratégias para a educação de alunos com neces- 
sidades educacionais especiais. Uma delas é que as pessoas com AH/SD são egoístas, solitários, individualistas e que se consideram superiores às demais (crenças populares muito comuns), comportamentos decorrentes de características de personalidade e de outras influências, que podem estar presentes em qualquer pessoa, mas que não são resultado das $\mathrm{AH} / \mathrm{SD}$. A forte vinculação da aprendizagem à infra-estrutura material (materiais, equipamentos e mobiliários; bibliotecas, laboratórios, ateliers e materiais escritos "que estimulem a criatividade"), como recurso facilitador do acesso ao currículo e a ausência de indicação de estratégias pedagógicas para mediar esse acesso apontam para a ideia de que esse estudante se autoeduca, que já sabe tudo e apenas precisa de recursos materiais e ambientes facilitadores.

\section{preconceito ideológico}

Há um preconceito velado em relação aos estudantes com AH/SD e a seu atendimento que tem um fundamento pretensamente ideológico que associa a sua existência à defesa da meritocracia, ou seja, a um sistema que valoriza o "mérito" como critério de hierarquia para a adjudicaçáo de posiçóes mais valorizadas dentro desse sistema. Em todas as sociedades e sistemas de governo democráticos atuais, a seleção de seus servidores pelo seu desempenho em concursos públicos; o ingresso às universidades de acordo com as pontuaçóes nos exames vestibulares; a seleção de funcionários nas empresas e a própria avaliação escolar por notas, por exemplo, não deixam de ser autênticos sistemas meritocráticos. Entretanto, não é considerado meritocrático o AEE aos alunos com deficiência, muito embora recebam um atendimento diferenciado que, em tese, é "melhor" que aquele oferecido na sala de aula comum, porque se sabe que, em função das necessidades diferenciadas desses estudantes, o atendimento educacional também deve ser diferente. Por que, entáo, o mesmo AEE, quando destinado aos alunos com AH/SD é considerado meritocrático? A resposta a esta pergunta está vinculada a própria compreensão do que sejam as AH/SD; do que seja "mérito" e do próprio sentimento que a deficiência gera na nossa sociedade.

Um mito que costuma estar muito enraizado é aquele de que a pessoa com AH/SD é "melhor" do que as demais; logo, dentro de um sistema meritocrático, ela mereceria (conforme a origem da palavra mérito) um atendimento educacional melhor do que o oferecido aos demais alunos e isso não é bem visto nem aceito por algumas pessoas que pregam a igualdade de direitos e a abolição de privilégios sociais que a democracia deveria assegurar. Náo consideramos a deficiência como um "mérito", mas, na mesma linha de pensamento, reconhecemos que a pessoa com deficiência "merece" ou tem direito a um atendimento educacional "melhor". O que ocorre é que, como sociedade, sentimos "pena" e "culpa" em relação à pessoa com deficiência, porque ela não é "normal" como todos nós, e isso faz que procuremos nos redimir perante esse "corpo dócil, anormal e desviante" que Foucault descreve. O mesmo não ocorre em relação à pessoa com AH/SD que, apesar de também ser "anormal e desviante", não parece ser tão "manipulável" e, por isso, gera sentimentos opostos e contraditórios, de velada inveja e admiração, de amor e de ódio, e o mesmo merecimento que teria a um atendimento educacional especializado, em razão das mesmas necessidades diferenciadas das pessoas com deficiência, que a escola não consegue atender na classe comum, transforma-se em meritocracia. 
Alega-se que atender os alunos com AH/SD seria uma espécie de elitismo, o que também não tem quaisquer justificativas. O termo elitismo deriva de "elite" que, em francês, quer dizer "o que há de melhor" e o elitismo, entendido como favoritismo de uma "minoria", encerra em si um conceito semelhante ao de meritocracia, pois atribui a um grupo minoritário entendido como "melhor" determinadas vantagens sobre outros grupos sociais. Por trás desse conceito, aparecem novamente duas medidas e dois pesos diferentes. Enquanto o AEE para os alunos com deficiência não se considera elitista, porque essas pessoas não são consideradas "melhores", o é para os estudantes com AH/SD, porque estes, sim, são entendidos como "melhores" e como uma "minoria". Entretanto, de fato, não são nem melhores e nem minoria, pois constituem quase o dobro de todas as matrículas de alunos classificados como pessoas com deficiências.

\section{A modo de conclusão, mas ainda esperando...}

A real inclusão dos alunos com $\mathrm{AH} / \mathrm{SD}$, entâo, requer a correta identificação e registro desses estudantes nos censos escolares, visto que esses são os dados que alegadamente fundamentam a formulação das políticas públicas e o retorno do quesito $\mathrm{AH} / \mathrm{SD}$ ao formulário do censo do ensino superior. Ao contrário das demais áreas da Educação Especial, a identificação é parte integrante do atendimento educacional especializado, porque não pode ser feita apenas por um laudo, visto que não se trata de uma patologia ou deficiência aferível, mas ao longo de um processo contínuo e relativamente demorado que precisa avaliar a presença, intensidade e consistência dos indicadores de Altas Habilidades/Superdotação, no contexto escolar, que devem ser registrados em parecer pedagógico. Durante esse processo, geralmente desenvolvido em Sala de Recursos Multifuncional, sala de recursos específica para as AH/SD ou centro de atendimento, o estudante já está recebendo um atendimento educacional especial, pelo que deve ser registrado no Censo Escolar como um aluno com $\mathrm{AH} /$ $\mathrm{SD}$. Isso não impede que, ao final da identificação, o profissional que realiza o $\mathrm{AEE}$ constate que os indicadores de $\mathrm{AH} / \mathrm{SD}$ não se confirmaram e, consequentemente, o aluno deixe de ser registrado nessa categoria no Censo escolar no próximo ano.

Requer, também, a promoção de um conhecimento mais aprofundado da legislação, das normas e documentos norteadores das políticas públicas nos diferentes contextos regionais e de sua fiscalização pelos poderes públicos, a necessária formação inicial e continuada de professores, profissionais e gestores sobre as AH/SD e suas necessidades, dever dos órgãos educacionais municipais, estaduais e federais e das universidades brasileiras, responsáveis pela geração e divulgação do conhecimento na sociedade.

Demanda o apoio técnico e financeiro e a fiscalização do trabalho desenvolvido pelos Núcleos de Atividades de Altas Habilidades/Superdotaçáo, instrumentos concretos da política pública, que náo podem ficar sujeitos à vontade política dos governos estaduais e/ou de seus gestores.

A real inclusão dos estudantes com AH/SD exige mecanismos legais que garantam o acesso ao atendimento educacional especializado da grande maioria de es- 
tudantes com AH/SD brasileiros, filhos de famílias de classes desfavorecidas, que não possuem recursos financeiros e/ou culturais para garantir esse direito, assim como a eliminação das barreiras econômicas, culturais e atitudinais como objetivo dos dispositivos que garantem a acessibilidade das pessoas com necessidades educacionais especiais.

Requer, urgentemente, a indispensável inclusão de módulos de formação específica para o atendimento educacional especializado nos cursos de capacitação e especialização oferecidos pelos órgãos públicos, apoiados por profissionais especializados com reconhecimento na área.

E, finalmente, requer a eliminação do infundamentado preconceito ideológico, tão nefasto - por ser preconceito - de forma a garantir, segundo os preceitos historicamente defendidos pelo ideal democrático, o direito que cada pessoa tem de acordo com suas necessidades.

\section{Referências}

BRASIL. Lei 10.172, de 09 de janeiro de 2001. Aprova o Plano Nacional de Educação e dá outras providências. Brasília: MEC, 2001.

. Lei 5692, de 11 de agosto de 1971. Fixa as diretrizes e bases para o ensino de $1^{\circ}$ e $2^{\circ}$ grau e dá outras providências. Brasília, DF: Diário Oficial da Uniáo, 1971.

. Lei no 9394/96, de 20 de dezembro de 1996. Estabelece as diretrizes e bases da educação nacional. Brasília: Diário Oficial da Uniáo, 1996.

Conselho Nacional de Educaçáo. Câmara de Educação Básica. Resolução No 4, de 2 de outubro de 2009. Institui Diretrizes Operacionais para o Atendimento Educacional Especializado na Educação Básica, modalidade Educação Especial. Brasília: MEC/CNE, 2009.

Instituto Nacional de Estudos e Pesquisas Educacionais Anísio Teixeira (INEP). Censo escolar da educação básica 2012 - resumo técnico. Brasília: INEP, 2013.

Ministério de Educaçáo. Secretaria de Educação Especial. Diretrizes nacionais para a educação especial na educação básica. 2. Brasília: MEC/SEESP, 2002.

Ministério de Educação. Secretaria de Educação Especial. Publicaçóes. 2010. http://portal.mec.gov.br/ index.php?option=com_content \&view=article\&id=12625\&Itemid=860 (acesso em 30 de outubro de 2010).

Ministério de Educação. Secretaria de Educação Fundamental/ Secretaria de Educação Especial. Parâmetros Curriculares Nacionais - Adaptaçôes curriculares Estratégias para a educação de alunos com necessidades educacionais especiais. Brasília: SEF/SEESP, 1998.

IBGE - Instituto Brasileiro de Geografia e Estatística. "Brasil em Síntese.” Instituto Brasileiro de Geografia e Estatística. 2008. Disponível em: <www.ibge.gov.br/brasil_em_sintese/tabelas/Tabela_trab_clsse_rend.shtm.> Acesso em: 26 out. 2010).

INSTITUTO NACIONAL DE ESTUDOS E PESQUISAS EDUCACIONAIS ANÍSIO TEIXEIRA (INEP). Resultados do Censo de Educaçáo Básica 2009. 2009. Disponível em: www.inep.gov.br/download/censo/2009/TEXTO_DIVULGACAO_EDUCACENSO_20093.pdf. Acesso em: 13 maio, 2010).

MARLAND, S. P. Jr. Education of the gifted and talented: Report to the Congress of the United States by the U.S. Commissioner and background papers submitted to the U.S. Office of Education. Washington, DC: U.S. Government Printing Office, 1972.

MENDES, E. Políticas públicas: articulação com a produção científica em Educação Especial. Revista Brasileira de Educaçáo Especial (UNESP-Marília-Publicaçōes), v. 6, n. 1, 2000.

MOREIRA, L. C. Cursos de licenciatura com bases inclusivas: impressóes de alunos com necessidades educacionais especiais e de seus professores. In: MEYRELLES, D. et al. (Org.). Inclusão, práticas pedagógicas e trajetórias de pesquisa, Porto Alegre: Mediaçáo, 2009. p. 261-270. 
PRIETO, R. G. A construçáo de políticas públicas de educaçáo para todos. Educaçâo on-line. 2002. Disponível em: <http://www.educacaoonline.com.br.> Acesso em: 28 mar. 2002.

\section{Correspondência}

Susana Graciela Pérez Barrera Pérez - Rua Dr. Ernesto Di Primio Beck, 315, CEP: 91510-490 - Porto Alegre - Rio Grande do Sul, Brasil.

E-mail: susanapb@terra.com.br - soraiafreitas@yahoo.com.br

Recebido em 06 de abril de 2014

Aprovado em 18 de junho 2014 
